\title{
Infant feeding practice of HIV positive mothers and its determinants in selected health institutions of Addis Ababa, Ethiopia
}

\author{
Yetayesh Maru $^{1}$, Jemal Haidar ${ }^{2}$
}

\begin{abstract}
Background: Avoidance of all breast-feeding by HIV infected mothers is recommended when replacement feeding is acceptable, feasible, affordable, sustainable, and safe. Whereas for women whose HIV status is unknown or negative, exclusive breastfeeding for the first six months is the single infant feeding option recommended.

Objective: To assess the infant feeding practice of HIV positive mothers and its determinants.

Methods: A cross sectional study with analytical component was conducted in 13 purposively selected health institutions with ART and PMTCT facilities in Addis Ababa during March, 2008. A total of 327 HIV positive mothers with their young infants visiting the respective health institutions were recruited in order of arrival, and assessed for their infant feeding practices.

Results: Exclusive replacement feeding (ERF), exclusive breastfeeding (EBF) and mixed feeding (MF) were 46.8\%, $30.6 \%$, and $15.3 \%$ respectively. The predictors for choosing ERF were mode of delivery $(p<0.05)$, household income $(\mathrm{p}<0.05)$ and disclosure of HIV status to spouse $(\mathrm{p}<0.01)$. The predictor for EBF, was mode of delivery $(\mathrm{p}<0.05)$ while for MF, disclosure of HIV status to spouse $(p<0.05)$, parental infant feeding attitude $(p<0.01)$ and infant illnesses $(\mathrm{p}<0.01)$ were the predictors. Furthermore, sticking to mothers' informed safer feeding options is challenged by some social factors.

Conclusion: The present study delineated the predictors involved in making safer choices for infant-feeding options. To achieve success in exclusivity of feeding options, mothers' decision should be respected and pressure from the family/neighbors to introduce other food to the infant needs to be discouraged. Furthermore, the risks involved in each infant feeding option should be communicated and advocated to the mother/father during PMTCT to make informed choices. [Ethiop. J. Health Dev. 2009;23(2):107-114]
\end{abstract}

\section{Introduction}

The balance between life saving benefits and the risk of transmission through breastfeeding complicates infant feedings in communities affected by HIV (1-5). Cognizant of the problem, WHO, UNICEF, UNAIDS and UNFPA in 2003 developed a guideline in the context of infant feeding by women whose HIV status is unknown and HIV positive women. The feeding option for women who are HIV negative or unknown status is to exclusively breastfeed (EBF) their newborn for the first six month, introduce complementary foods after six months and continue breastfeeding (BF) for two years and beyond. The recommended option for HIV positive women is to avoid $\mathrm{BF}$ when replacement feeding (RF) is Acceptable, Feasible, Affordable, Sustainable and Safe (AFASS). Nonetheless, when AFASS criteria cannot be met, mothers are advised to exclusively BF and avoid mixed feedings. Other feeding options recommended are to use heat treated expressed breast milk or wet nursing of the newborn by HIV negative when the AFASS criteria is not possible (1-7).

In line with the global recommendations, the Federal Ministry of Health of Ethiopia has adopted and developed a strategy of infant and young child feeding to be used in the country $(8,9)$. According to the national strategy, informed choices that suit the circumstances of the mother is emphasized and the advice to be given for the mothers should be tailored to individual needs to balance the risk of replacement feeding with the risk via BF.

Several studies reported the practice of feeding infants in the context of HIV positive mothers. Based on a Zambian study, infant-feeding practices of mothers of known HIV status that were counseled, $35 \%$ of them EBF their infants below 4 months (10). Another study in Cameroon demonstrated about $87.2 \%$ of the HIV positive mothers opted for ERF since birth, $8.5 \%$ chose EBF, while the rest $4.3 \%$ practiced mixed feeding. When the Cameroon figure is compared to Uganda's report, the prevalence of EBF among the HIV positive mothers in Uganda is four folds, $35.1 \%$ (11).

According to the baseline national PMTCT survey of infant feeding practice of mothers with unknown HIV status, the overall prevalence rate of EBF is $36.4 \%$ with marked significant regional variations. The proportion of mothers who fed their infants breast milk (BM) and water, BM and any other liquids, BM and solids and ERF are $17 \%, 28 \%, 16 \%$ and $4 \%$ respectively $(13,14)$. Nonetheless, information on feeding practices of HIV positive mothers has not been documented. Because of such a gap in information on the extent of the problem,

\footnotetext{
${ }^{\top}$ Health's Nutrition coordinator, Food for the hunger/Ethiopia, P.O. Box 4181, E-mail: yetayesh2005@yahoo.com;

${ }^{2}$ School of Public Health, Addis Ababa University, P.O. Box 27285-1000, Addis Ababa, Ethiopia E-mail, hjemal@gmail.com
} 
this study was necessitated with the objectives to assess the infant feeding practice of HIV positive mothers including the determinants and provide evidence-based information that can be used in the future by the line ministries and NGO's for program initiatives.

\section{Methods}

A cross sectional study with analytical component was conducted in purposively selected 13-government health institutions (5 hospitals and 8 health centers) with ART and PMTCT facilities in Addis Ababa between March 1 and 30,2008. The government health institutions were primarily selected on the basis of the availability of the services and adequate client flow at the time of the study.

The city is composed of 10 sub-cities and 100 kebeles with an estimated population of 3.5 million. It has a total of 36 hospitals (13 public and 26 private), 27 health centers ( 24 public and 3 private), and 450 private clinics (12). From the 63 health institutions (hospitals and health centers), only 38 potential hospitals and health centers (13 public and 1 private hospitals; and 24 health centers) having large number of client flow rendering PMTCT and ART services for the exposed infants were reregistered. From the registry, five public hospitals and eight health centers fulfilling the above criteria were purposively selected in consultation with Addis Ababa Regional Health Bureau. The one private hospital was excluded due to low client flow and absence of ART service at the time of the study.

Recruitment continued until the required sample was obtained. The sample size was determined on the assumption of a prevalence rate of $50 \%$ (since the status is not known) with $95 \%$ confident level, $5 \%$ precision and a non-response rate of $5 \%$, a total of 338 was needed. A total of 327 HIV positive mothers with their young infants visiting the respective health institutions were recruited in order of arrival, and assessed for their infant feeding practices and HIV status of their children.

A pre-tested structured questionnaire was used to collect socio-demographic, feeding practices and other relevant infant related information. Data collectors were recruited from the respective health institutions and were trained on data collection techniques for 2 days. The trained 13 nurses and 3 health officers from the respective health institutions collected the data under the close supervision of the principal investigator. Each questionnaire filled was checked for completeness of the information by the principal investigator. Probing questions were also asked to reduce error arising from respondent's memory lapse and the information collected was rechecked in $10 \%$ of randomly selected subjects.

Key-informants interviews were conducted in all captured health institution. A total of 13 active counselors drawn from the PMTCT units were interviewed by the principal investigator using semi- structured questionnaire adopted from various related researches. The responses were then grouped and described accordingly.

Data were cleaned manually and then entered into the computer and analyzed using SPSS version 13. Descriptive statistics was used to show the prevalence of various characteristics. Bivarate analysis was used to see the associations of different variables. Odds ratio with $95 \%$ confidence interval was computed to assess the presence and degree of association between variables. Logistics regression model was also applied to identify the important determinants for various feeding options. In addition, standard tabulations were generated in which the outliers were identified. A p-value of below 0.05 denoted significance in differences.

Ethical issues: The ethical review committee of the Addis Ababa University Medical Faculty, and Region 14 Health Bureau approved the study for its ethical and scientific merit. The selected health institutions were communicated and have supported the undertakings of this study in writing: an additional informed verbal consent was also obtained from the respective mothers/guardians and an assent of the child of all subjects for their participation after the nature of the study was fully explained in their local languages. The right of mothers to withdraw from the study at any time was communicated and respected. Mothers who were not feeling well at the time of the study were advised to see their doctors.

All parents/guardians were encouraged to start the slow processes of disclosing the HIV status of the child. Subsequent interviews of the key informants were conducted in private and the right of the respondents to refuse at anytime was respected. Secondary data was also reviewed for the HIV status of children.

\section{Results}

From the total 338 HIV positive mothers recruited, 327 participated actively making the response rate of $96.7 \%$. Figure 1 summarizes the various infant feeding practices of the HIV positive mothers. Nearly half (46.8\%) of the mothers practiced Exclusive Replacement Feeding (ERF); 30.6\% used Exclusive Breast-Feeding (EBF); $15.3 \%$ used mixed feeding (MF) and the rest $7.3 \%$ practiced breast-feeding for 2 months followed by replacement feeding thereafter. Expressed Breast-milk feeding and wet-nursing were practiced by $4.3 \%$ and $0.3 \%$ respectively.

Among mothers who practiced mixed feeding, the commonest reasons cited were neighbor's advice in $40 \%$; while insufficient breast milk, husband imposition, mother's illness and both mother's and infant's illness were mentioned by $26 \%, 14 \%, 8 \%$ and $6.0 \%$ respectively (Figure 2). 


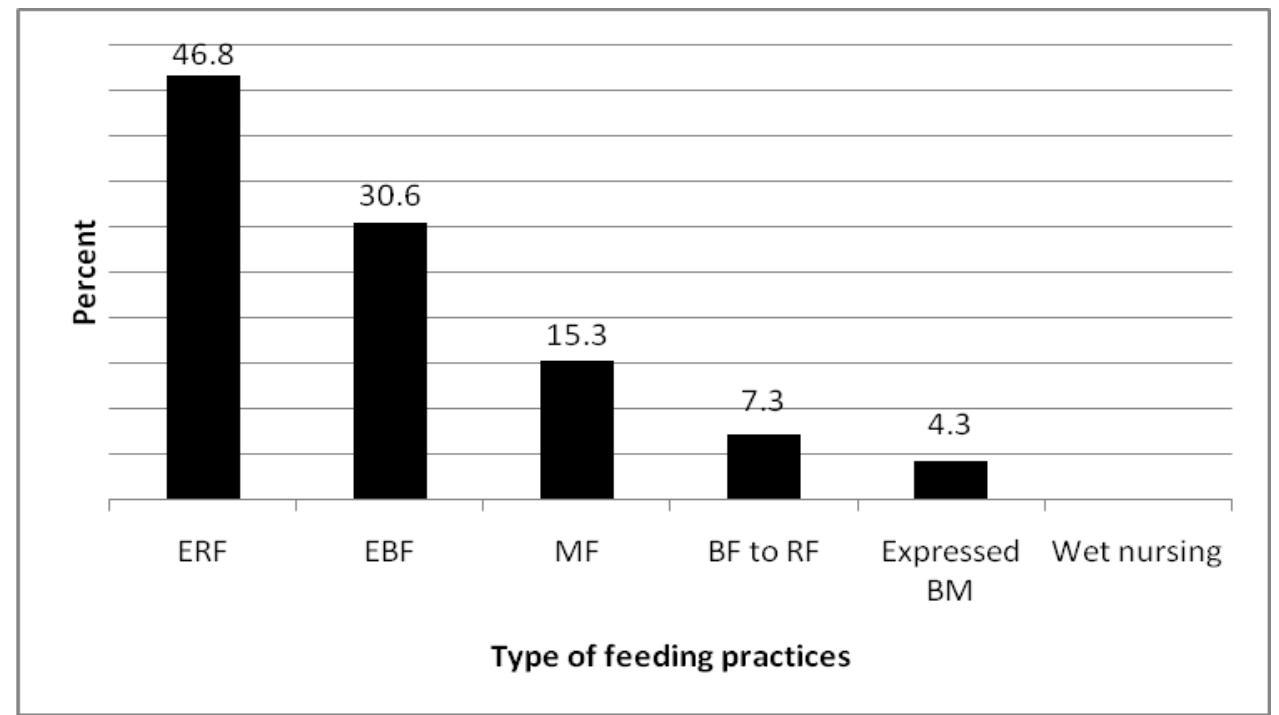

Figure 1: Type of infant feeding practices of HIV mothers, Addis Ababa, 2008

Exclusive breastfeeding; $\quad \mathrm{EBF}=$ Exclusive breast feeding; $\quad \mathrm{MF}=$ Mixed feeding; $\quad \mathrm{BM}=\mathrm{Breast}$ milk

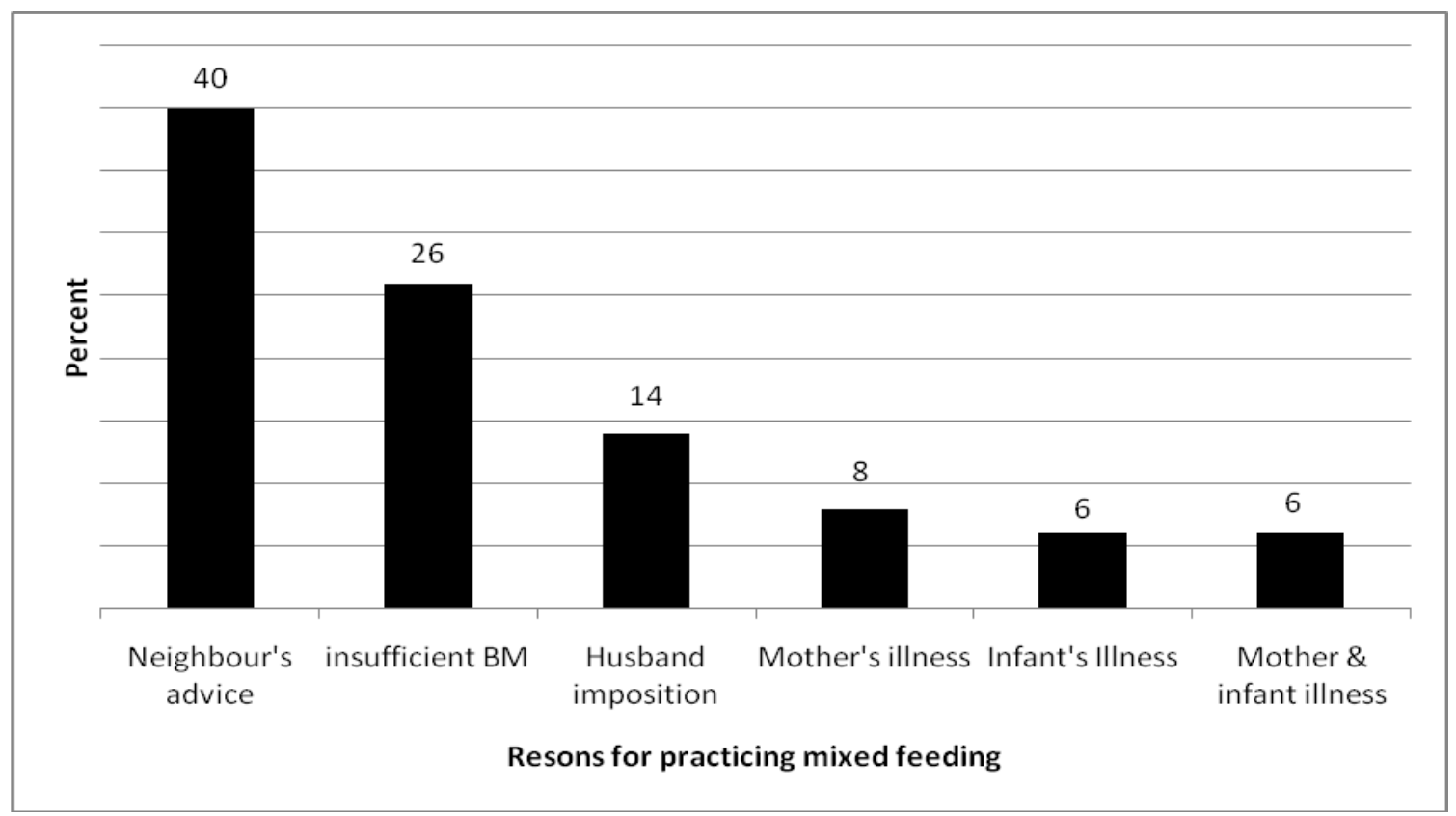

Figure 2: Type of reasons forwarded for mixed feeding by HIV positive mothers, Addis Ababa, 2008

$\mathrm{BM}=$ Breast milk

Table 1 illustrates the various factors associated with ERF. As shown, educational status of both partners, household income, place and mode of delivery, antenatal care (ANC) follow-up and time of first visit, disclosure of HIV status to spouse, and infant feeding attitude were associated with ERF $(\mathrm{p}<0.05)$. Nonetheless, in the hierarchal models, only mode of delivery, household income and disclosure of HIV status to spouse retained their association as predictors. Mothers who delivered by $\mathrm{C} / \mathrm{S}$ were 4.1 times more likely to practice ERF than the referent groups. $(\mathrm{OR}=4.1,95 \% \mathrm{CI}=1.7-10.2)$, Mothers with household income 501-1000 birr were 2 times more likely to practice ERF than the referent groups
$(\mathrm{OR}=2.2,95 \% \mathrm{CI}=1.0-4.5)$ and those who disclosed their HIV status to their spouses were 3.8 times more likely to apply ERF than their counterparts $(\mathrm{OR}=3.8,95 \% \mathrm{CI}=1.9$ 7.1).

As displayed in Table 2, education of partners, income, mode of delivery and knowledge of PMTCT were associated with EBF $(p<0.05)$. However, in the multiple regression analysis model, only mode of delivery remained as a predicting factor for EBF. Mothers who delivered by $\mathrm{C} / \mathrm{S}$ were $80 \%$ less likely to practice $\mathrm{EBF}$ than those who delivered by SVD $(\mathrm{OR}=0.2,95 \% \mathrm{CI}=0.1$ $0.7)$. 
Table 1: Factors associated with practicing exclusive replacement feeding among HIV positive mothers, Addis

\begin{tabular}{|c|c|c|c|}
\hline Variable & ERF & COR (95\% Cl) & AOR (95\% Cl) \\
\hline \multicolumn{4}{|l|}{ Age } \\
\hline $15-24$ & $34(45.9)$ & 1 & 1 \\
\hline $25-35$ & $105(46.7)$ & $1.01(0.6,1.7)$ & $0.8(0.4,1.7)$ \\
\hline $35+$ & $14(50.0)$ & $1.18(0.49,2.81)$ & $1.9(0.5,7.4)$ \\
\hline \multicolumn{4}{|l|}{ Marital Status } \\
\hline Single & $8(34.8)$ & 1 & 1 \\
\hline Married & $132(49.6)$ & $1.82(0.75,4.44)$ & $107.9(0.5,4.4 \mathrm{E}+14)$ \\
\hline Others & $13(34.2)$ & $0.98(0.33,2.90)$ & \\
\hline \multicolumn{4}{|l|}{ Education of Mothers } \\
\hline None & $18(27.7)$ & 1 & 1 \\
\hline Read and write & $9(37.5)$ & $1.57(0.58,4.21)$ & $0.8(0.2,3.3)$ \\
\hline 1-8 grade & $39(41.1)$ & $1.82(0.92,3.59)$ & $0.8(0.3,2.0)$ \\
\hline $9-10$ & $63(56.3)$ & $3.36(1.74,6.49) \quad * *$ & $0.9(0.3,2.5)$ \\
\hline $10+2 \&$ above & $24(77.4)$ & $7.51(2.84,19.82)$ ** & $1.3(0.3,5.9)$ \\
\hline \multicolumn{4}{|l|}{ Education of spouse } \\
\hline None & $3(23.1)$ & 1 & 1 \\
\hline Read and write & $4(21.1)$ & $0.89(0.16,4.85)$ & $0.3(0.0,2.5)$ \\
\hline $1-8$ grade & $21(38.9)$ & $2.12(0.52,8.6)$ & $0.8(0.1,4.8)$ \\
\hline $9-10$ & $67(54.5)$ & $3.86(1.01,14.71)$ * & $1.7(0.3,9.3)$ \\
\hline $10+2 \&$ above & $37(62.7)$ & $5.61(1.39,22.59)$ ** & $1.1(0.2,7.6)$ \\
\hline \multicolumn{4}{|l|}{ Occupation of mothers } \\
\hline House wife & $104(46.8)$ & 1 & 1 \\
\hline Private employee & $18(46.2)$ & $0.99(0.50,1.96)$ & $1.2(0.4,3.6)$ \\
\hline Government employee & $8(80.0)$ & $4.62(0.96,22.25)$ & $1.3(0.2,10.7)$ \\
\hline Daily laborer & $8(34.8)$ & $0.62(0.25,1.51)$ & $2.7(0.6,11.3)$ \\
\hline Others & $15(45.5)$ & $0.96(0.5,2.0)$ & $1.31(0.4,4.8)$ \\
\hline \multicolumn{4}{|l|}{ Household income } \\
\hline$<=500$ & $81(38.6)$ & 1 & 1 \\
\hline $500-1000$ & $54(57.4)$ & $2.06(1.26,3.37)^{\star *}$ & $2.2(1.0,4.5)^{*}$ \\
\hline$>=1001$ & $18(78.3)$ & $5.73(2.05,16.04)^{\star *}$ & $1.8(0.4,7.3)$ \\
\hline \multicolumn{4}{|l|}{ Place of delivery } \\
\hline At home & $4(16.7)$ & 1 & 1 \\
\hline Private hospital & $4(57.1)$ & $4.67(1.06,42.06)^{\star}$ & $0.7(0.0,10.7)$ \\
\hline Private clinic & $2(50.0)$ & $4.99(0.54,46.71)$ & $2.1(0.1,49.7)$ \\
\hline Government HC & $19(27.1)$ & $1.86(0.56,6.16)$ & $0.3(0.1,2.3)$ \\
\hline Government hospital & $124(55.9)$ & $6.21(2.06,18.76)^{\star *}$ & $0.7(0.1,4.2)$ \\
\hline \multicolumn{4}{|l|}{ Mode of delivery } \\
\hline SVD & $89(39.2)$ & 1 & 1 \\
\hline $\mathrm{C} / \mathrm{S}$ & $44(81.5)$ & $6.95(3.33,14.52)^{\star *}$ & $4.4(1.7,11.4)^{*}$ \\
\hline Episiotomy & $19(44.2)$ & $1.25(0.65,2.42)$ & $1.0(0.4,2.3)$ \\
\hline Others & $1(33.3)$ & $0.79(0.07,8.84)$ & $0.4(0.0,6.9)$ \\
\hline \multicolumn{4}{|l|}{ Time of first antenatal visit } \\
\hline First trimester & $70(58.83)$ & 1 & 1 \\
\hline Second trimester & $67(42.9)$ & $0.6(0.3,0.9)^{*}$ & $0.6(0.3,1.1)$ \\
\hline Third trimester & $13(40.6)$ & $0.5(0.2,1.1)$ & $0.3(0.1,1.0)$ \\
\hline \multicolumn{4}{|c|}{ HIV status Disclosure to spouse } \\
\hline No & $47(31.3)$ & 1 & 1 \\
\hline Yes & $105(59.3)$ & $3.46(2.14,5.62)^{\star *}$ & $3.6(1.9,7.0)^{\star *}$ \\
\hline \multicolumn{4}{|c|}{ PMTCT Knowledge of mother ${ }^{a}$} \\
\hline Insufficient & $59(41.5)$ & 1 & 1 \\
\hline Sufficient & $94(50.8)$ & $1.42(0.92,2.21)$ & $0.7(0.3,1.3)$ \\
\hline \multicolumn{4}{|c|}{ Attitude towards infant feeding ${ }^{a}$} \\
\hline Negative & $13(31.0)$ & 1 & 1 \\
\hline \multirow{2}{*}{\multicolumn{4}{|c|}{ Infant feeding option awareness ${ }^{a}$}} \\
\hline & & & \\
\hline No & $7(35.0)$ & 1 & 1 \\
\hline Yes & $146(47.6)$ & $1.66(0.65,4.28)$ & $1.1(0.3,4.1)$ \\
\hline
\end{tabular}

$\mathrm{a}=$ mother; $\mathrm{HC}=$ health centers; ${ }^{*} \mathrm{P}$ value $<0.05 ;{ }^{* *} \mathrm{P}$ value $<0.01$ 


\begin{tabular}{|c|c|c|c|}
\hline Variable & EBF & COR $(95 \% \mathrm{Cl})$ & AOR (95\% Cl) \\
\hline \multicolumn{4}{|l|}{ Age of mother } \\
\hline $15-24$ & $24(32.4)$ & 1 & 1 \\
\hline $25-35$ & $69(30.7)$ & $0.94(0.54,1.65)$ & $1.1(0.5,2.4)$ \\
\hline $35+$ & $7(25.0)$ & $0.69(0.26,1.86)$ & $0.6(0.1,2.6)$ \\
\hline \multicolumn{4}{|l|}{ Marital Status } \\
\hline Single & $10(43.5)$ & 1 & 1 \\
\hline Married & $79(29.7)$ & $0.56(0.23,1.33)$ & $0.0(0.0,1.3 \mathrm{E}+30)$ \\
\hline Others & $11(28.9)$ & $0.53(0.18,1.56)$ & \\
\hline \multicolumn{4}{|l|}{ Education of Mothers } \\
\hline None & $27(41.5)$ & 1 & 1 \\
\hline Read and write & $8(33.3)$ & $0.70(0.26,1.88)$ & $0.7(0.2,3.0)$ \\
\hline $1-8$ grade & $36(37.9)$ & $0.86(0.45,1.64)$ & $1.4(0.5,3.9)$ \\
\hline $9-10$ & $27(24.1)$ & $0.45(0.23,0.86)^{\star}$ & $0.8(0.3,2.4)$ \\
\hline $10+2 \&$ above & $2(6.5)$ & $0.15(0.04,0.55)^{\star *}$ & $0.5(0.1,3.2)$ \\
\hline \multicolumn{4}{|l|}{ Education of spouse } \\
\hline None & $9(69.2)$ & 1 & 1 \\
\hline Read and write & $12(63.2)$ & $0.76(0.17,3.42)$ & $0.9(0.1,6.3)$ \\
\hline $1-8$ grade & $19(35.2)$ & $0.24(0.07,0.89)^{*}$ & $0.3(0.1,1.8)$ \\
\hline $9-10$ & $29(23.6)$ & $0.14(0.04,0.50)^{\star}$ & $0.2(0.0,1.0)$ \\
\hline $10+2 \&$ above & $12(20.3)$ & $0.11(0.03,0.43)^{* *}$ & $0.3(0.0,1.8)$ \\
\hline \multicolumn{4}{|l|}{ Occupation of mother } \\
\hline House wife & $73(32.9)$ & 1 & 1 \\
\hline Private employee & $13(33.3)$ & $1.0(0.49,2.06)$ & $0.8(0.3,2.7)$ \\
\hline Government employee & 0 & $0.01(0.0,1.1 \mathrm{E}+07)$ & $0.0(0.0,7.9 . E+12)$ \\
\hline Daily laborer & $6(26.1)$ & $0.7(0.3,1.9)$ & $0.3(0.0,1.5)$ \\
\hline Others & $8(24.2)$ & $0.6(0.3,1.5)$ & $0.8(0.2,3.5)$ \\
\hline \multicolumn{4}{|l|}{ Household income } \\
\hline$<=500$ & $76(36.2)$ & 1 & 1 \\
\hline $500-1000$ & $22(23.4)$ & $0.57(0.33,0.99)^{*}$ & $0.6(0.3,1.3)$ \\
\hline$>=1001$ & $2(8.7)$ & $0.17(0.04,0.74)^{*}$ & $0.7(0.1,4.0)$ \\
\hline \multicolumn{4}{|l|}{ Time of first antenatal visit } \\
\hline First trimester & $32(26.7)$ & 1 & 1 \\
\hline Second trimester & $47(30.1)$ & $1.1(0.7,1.9)$ & $1.0(0.5,1.8)$ \\
\hline Third trimester & $13(40.6)$ & $1.8(0.8,4.1)$ & $2.8(0.8,9.1)$ \\
\hline \multicolumn{4}{|l|}{ Place of delivery } \\
\hline At home & $8(33.3)$ & 1 & 1 \\
\hline Private hospital & $1(14.3)$ & $0.33(0.34,3.26)$ & $0.0(0.0,9.1 \mathrm{E}+17)$ \\
\hline Private clinic & $1(25.0)$ & $0.67(0.06,7.47)$ & $0.0(0.0,3.1 \mathrm{E}+26)$ \\
\hline Government HC & $35(50.0)$ & $2.00(0.76,5.27)$ & $6.1(0.8,45.5)$ \\
\hline Government hospital & $55(24.8)$ & $0.67(0.27,1.66)$ & $2.9(0.4,20.5)$ \\
\hline \multicolumn{4}{|l|}{ Mode of delivery } \\
\hline SVD & $80(35.2)$ & 1 & 1 \\
\hline $\mathrm{C} / \mathrm{S}$ & $4(7.4)$ & $0.14(0.05,0.41)^{* *}$ & $0.2(0.1,0.7)^{*}$ \\
\hline Episiotomy & $15(34.9)$ & $0.97(0.49,1.91)$ & $1.1(0.5,2.7)$ \\
\hline Others & $1(33.3)$ & $0.90(0.08,10.09)$ & $1.0(0.1,26.3)$ \\
\hline \multicolumn{4}{|c|}{ HIV status Disclosure to spouse } \\
\hline No & $55(36.7)$ & 1 & 1 \\
\hline Yes & $45(25.4)$ & $0.64(0.39,1.05)$ & $0.6(0.3,1.2)$ \\
\hline \multicolumn{4}{|l|}{ Maternal illness } \\
\hline No & $87(32.7)$ & 1 & 1 \\
\hline Yes & $13(21.3)$ & $0.5(0.3,1.1)$ & $0.79(0.3,1.6)$ \\
\hline \multicolumn{4}{|l|}{ Infant illness } \\
\hline No & $64(34.0)$ & 1 & 1 \\
\hline Yes & $36(26.3)$ & $0.7(0.4,1.1)$ & $10.6(0.3,1.1)$ \\
\hline \multicolumn{4}{|l|}{ Knowledge of PMTCT ${ }^{a}$} \\
\hline Insufficient & $53(37.3)$ & 1 & 1 \\
\hline Sufficient & $47(25.4)$ & $0.59(0.37,0.94)^{*}$ & $0.6(0.3,1.2)$ \\
\hline \multicolumn{4}{|c|}{ Attitude about infant feeding ${ }^{a}$} \\
\hline Negative & $13(31.0)$ & 1 & 1 \\
\hline Positive & $87(30.5)$ & $0.99(0.49,2.01)$ & $0.9(0.3,2.8)$ \\
\hline \multicolumn{4}{|c|}{ Infant feeding option awareness ${ }^{a}$} \\
\hline No & $8(40.0)$ & 1 & 1 \\
\hline Yes & $92(30.0)$ & $0.65(0.26,1.65)$ & $0.9(0.2,3.8)$ \\
\hline
\end{tabular}

$\mathrm{a}=$ mother; $\mathrm{HC}=$ health centers; ${ }^{*} \mathrm{P}$ value $<0.05 ;{ }^{*} \mathrm{P}$ value $<0.01$ 
Table 3: Factors associated with mixed-breast-feeding among HIV positive mothers, Addis Ababa, 2008

\begin{tabular}{|c|c|c|c|}
\hline Variable & MF & COR (95\% Cl) & AOR (95\% CI) \\
\hline \multicolumn{4}{|l|}{ Age of mother } \\
\hline $15-24$ & $11(14.9)$ & 1 & 1 \\
\hline $25-35$ & $33(14.7)$ & $0.98(0.47,2.06)$ & $1.8(0.5,6.2)$ \\
\hline $35+$ & $6(21.4)$ & $1.56(0.52,4.72)$ & $1.3(0.2,9.6)$ \\
\hline \multicolumn{4}{|l|}{ Marital Status } \\
\hline Single & $5(21.7)$ & 1 & 1 \\
\hline Married & $32(12.0)$ & $0.49(0.17,1.41)$ & $624(0.0, E)$ \\
\hline Others & $13(34.2)$ & $1.87(0.57,6.19)$ & \\
\hline \multicolumn{4}{|l|}{ Education of Mothers } \\
\hline None & $17(26.2)$ & 1 & 1 \\
\hline Read and write & $4(16.7)$ & $0.56(0.17,1.89)$ & $1.3(0.3,4.6)$ \\
\hline 1-8 grade & $15(15.8)$ & $0.53(0.24,1.16)$ & $0.8(0.3,2.3)$ \\
\hline $9-10$ & $11(9.8)$ & $0.31(0.13,0.71)^{\star *}$ & $0.8(0.3,2.2)$ \\
\hline $10+2 \&$ above & $3(9.7)$ & $0.30(0.08,1.12)$ & $0.8(0.1,5.3)$ \\
\hline \multicolumn{4}{|l|}{ Education of spouse } \\
\hline None & $1(7.7)$ & & \\
\hline Read and write & $1(5.3)$ & $0.67(0.04,11.72)$ & $934(0.0,5.1 \mathrm{E}+27)$ \\
\hline $1-8$ grade & $6(11.1)$ & $1.50(0.16,13.66)$ & $465(0.0,2.5 E+28)$ \\
\hline $9-10$ & $19(15.4)$ & $2.19(0.27,17.8)$ & $605(0.0,3.2 \mathrm{E}+28)$ \\
\hline $10+2 \&$ above & $5(8.5)$ & $1.11(0.12,10.39)$ & $582(0.0,3 \cdot 1 \mathrm{E}+28)$ \\
\hline \multicolumn{4}{|l|}{ Occupation of mother } \\
\hline House wife & $27(12.2)$ & 1 & 1 \\
\hline Private employee & $6(15.4)$ & $1.3(0.50,3.40)$ & $0.9(0.3,3.3)$ \\
\hline Government employee & $7(30.4)$ & $3.16(1.19,8.38)^{*}$ & $1.5(0.4,5.7)$ \\
\hline Daily laborer & $1(20.0)$ & $1.81(0.19,16.76)$ & $6.4(0.3,1.48)$ \\
\hline Others & $4(21.1)$ & $1.93(0.59,6.23)$ & $2.3(0.4,12.9)$ \\
\hline \multicolumn{4}{|l|}{ Household income } \\
\hline$<=500$ & $36(17.1)$ & 1 & 1 \\
\hline $500-1000$ & $13(13.8)$ & $0.78(0.39,1.54)$ & $0.8(0.3,2.3)$ \\
\hline$>=1001$ & $1(4.3)$ & $0.22(0.03,1.68)$ & $0.5(0.0,8.1)$ \\
\hline \multicolumn{4}{|l|}{ Place of delivery } \\
\hline At home & $11(45.8)$ & 1 & 1 \\
\hline Private hospital & $1(14.3)$ & $0.19(0.02,1.89)$ & $0.2(0.0,3.1)$ \\
\hline Government HC & $10(14.3)$ & $0.19(0.07,0.56)^{\star *}$ & $0.2(0.1,1.1)$ \\
\hline Government hospital & $28(12.6)$ & $0.17(0.07,0.42)^{\star *}$ & $0.3(0.1,1.1)$ \\
\hline \multicolumn{4}{|l|}{ Mode of delivery } \\
\hline SVD & $42(18.5)$ & 1 & 1 \\
\hline $\mathrm{C} / \mathrm{S}$ & $3(5.6)$ & $0.26(0.08,0.87)$ & $0.3(0.1,1.3)$ \\
\hline Episiotomy & $4(9.3)$ & $0.45(0.15,1.33)$ & $0.9(0.3,3.2)$ \\
\hline Others & $1(33.3)$ & $2.20(0.19,24.86)$ & $26(0.9,694)$ \\
\hline \multicolumn{4}{|l|}{ Antenatal follow up } \\
\hline No & $6(31.6)$ & 1 & 1 \\
\hline Yes & $44(14.3)$ & $0.36(0.13,1.0)^{*}$ & $1.5(0.3,7.6)$ \\
\hline \multicolumn{4}{|l|}{ Time of first antenatal visit } \\
\hline First trimester & $13(10.8)$ & 1 & 1 \\
\hline Second trimester & $25(16.0)$ & $1.57(0.77,3.2)$ & $1.1(0.4,2.9)$ \\
\hline Third trimester & $6(18.8)$ & $1.89(0.66,5.47)$ & $1.4(0.3,7.5)$ \\
\hline \multicolumn{4}{|c|}{ HIV status Disclosure to spouse } \\
\hline No & $40(26.7)$ & 1 & 1 \\
\hline Yes & $10(5.6)$ & $0.16(0.08,0.33)^{\star *}$ & $0.11(0.04,0.3)^{\star *}$ \\
\hline \multicolumn{4}{|l|}{ Knowledge of PMTCT ${ }^{a}$} \\
\hline Insufficient & $24(16.9)$ & 1 & 1 \\
\hline Sufficient & $26(14.1)$ & $0.80(0.44,1.47)$ & $1.4(0.5,3.8)$ \\
\hline \multicolumn{4}{|c|}{ Attitude about infant feeding ${ }^{a}$} \\
\hline Negative & $13(31.0)$ & 1 & 1 \\
\hline Positive & $37(13.0)$ & $0.33(0.16,0.69)^{\star *}$ & $0.31(0.1,0.8)^{*}$ \\
\hline \multicolumn{4}{|c|}{ Infant feeding option awareness ${ }^{a}$} \\
\hline No & $5(25.0)$ & 1 & 1 \\
\hline Yes & $45(14.7)$ & $0.52(0.18,1.49)$ & $0.5(0.1,3.6)$ \\
\hline Maternal illness & & & \\
\hline No & $33(12.4)$ & 1 & 1 \\
\hline Yes & $17(27.9)$ & $2.73(1.39,5.32)^{\star *}$ & $2.2(0.9,5.4)$ \\
\hline Infant illness & & & \\
\hline No & $22(11.7)$ & 1 & 1 \\
\hline Yes & $28(20.4)$ & $1.94(1.06,3.56)^{\star *}$ & $2.3(1.0,5.0)^{*}$ \\
\hline
\end{tabular}

$\mathrm{a}=$ mother; $\mathrm{HC}=$ health centers; ${ }^{*} \mathrm{P}$ value $<0.05 ;{ }^{*} \mathrm{P}$ value $<0.01$ 
Table 3 displays the various factors associated with MF. Although, education and occupation of mothers, ANC follow-up, disclosure of HIV status, delivered at hospital and mothers with positive attitude of infant feeding, and maternal and infant illnesses were associated with MF, in the bivariate models, only disclosure of HIV status, positive attitude about infant feeding and infant illnesses remained determinants. Disclosure of HIV status to spouse made mothers $89 \%$ less likely to practice MF than those who didn't $(\mathrm{OR}=0.11,95 \% \mathrm{CI}=0.04-0.3)$. Mothers whose infant was ill were 2.3 times more likely to practice $\mathrm{MF}$ than those whose infant was not ill $(\mathrm{OR}=2.3$, $95 \% \mathrm{CI}=1.0-5.0)$. Likewise, mothers who had positive attitude towards infant feeding were $69 \%$ less likely to practice mixed feeding than those who didn't have such attitude $(\mathrm{OR}=0.31,95 \% \mathrm{CI}=0.1-0.8)$.

Another important finding comes from our in-depth interview held with the counselors. It is interesting to note that, the majority of the counselors stated that choosing safer infant feeding options based on AFASS criteria was the biggest challenge encountered in all the sessions held during counseling. In most of the sessions held with mothers, affordability issue was the key point that mothers consider in deciding to choose the options. A 30-year old female counselor said that, "If a mother says 'I can afford the formula milk', the mother makes her own decision at the spot and opt for ERF. Otherwise, we usually encourage mothers to exclusively breast feed their infants."

Another interesting finding mentioned by one of the counselors was resistance of mothers to sticking to safer infant feeding options because of the counter information forwarded by some neighbors and from close family members. One of the incidents described by a 32-year old counselor was sad in that "a woman got divorced following disclosure of her HIV status to the spouse and as a result ended up in grave consequences such as unassisted labor".

\section{Discussion}

Formula or replacement feeding (RF) for infants of HIV positive mothers is the recommended choice because risks of HIV transmission far outweigh morbidity and mortality resulting from replacement foods in developed countries. However, in the developing world the debate continues regarding the benefits and risks of replacement versus breast-feeding. In the present study, nearly half of the mothers practiced ERF while EBF is slightly greater than a quarter concurring with findings of Botswana, Zambia, South Africa and Uganda studies where $50 \%$ of HIV positive mothers used ERF and 30-40\% EBF and few $(5 \%)$ practiced expressed breast milk feeding. Compared to the various practices of infant feeding options documented for some African countries, similar findings were found in our setting. This could partly be explained by the fact that most women mind affordability only. This assertion was also supported by the key- informants where the vast majority mentioned the single criteria to stick to infant feeding option was affordability and not the feasibility, availability, safety and sustainability. Therefore, more advocacy work is needed to change the attitude of mothers to explore the various feasible and sustainable options.

According to the WHO guidelines, the inclusion of any feeding in addition to breast-milk into the diet (with the exclusion of medicines) constitutes mixed feeding. The proportion of mothers practicing mixed feeding (15.3\%) was comparatively higher than what was reported from Cameroon (4.3\%) and lower than in the study from India (29\%). The explanation given for higher MF practice by most mothers was neighbors' influence and sometimesinsufficient milk. The other reasons forwarded were the increasing pressure from family members to introduce other liquids, and most importantly the fear of being exposed as HIV positive. In-depth interview shows how HIV-positive women face challenges by relatives and husbands $(17,18)$, and this calls for an immediate attention of policy makers and program initiatives.

The other important finding in this study was that ERF practice was significantly associated with HIV disclosure status of subjects to spouse, household income and mode of delivery whereas EBF practice was significantly associated only with mode of delivery. Mothers who had delivered by $\mathrm{C} / \mathrm{S}$ were more likely to practice replacement feeding than spontaneous vertex delivery (SVD) and less likely to use EBF than SVD. Similar findings were reported in Uganda, Cameroon and India $(11,17,18)$. Again, mothers having household income between 501-1000 birr were more likely to use ERF than the referent group. According to the key informant interview, this is due to almost all counselors focused on only the affordability issue of mothers for replacement feeding during infant feeding counseling.

When the husbands are not aware of the HIV status of their wives, they usually impose on inappropriate infant feeding. Or else spouses will suspect their wives to have HIV and results in dispute. Such interferences in opting for the safer feeding options were challenges as was mentioned by the counselors and therefore requires strengthened advocacy work through all available channels. In this study, more than one third of mothers didn't disclose their HIV status to their spouse. According to key informant interview findings, this is because of the fear of adverse social outcomes like divorce, physical violence and being forced to leave their home. The low economic status of women and their economic dependence on husbands make the life of women worse if divorced which results in raising the child alone. There was a case that a woman got divorced following disclosure of her HIV status to her spouse and faced unassisted labor because of being alone. In order to avoid such undesirable consequences, it is recommended that both partners should be counseled properly on the 
issue to get the support from their male partners and encourage uptake of treatment to prevent the transmission of HIV.

The current strategy to reduce mother to child transmission in most countries is linked to voluntary HIV counseling and testing all pregnant mothers during the antenatal period. In this study, the majority $(87.2 \%)$ of study subjects complied with the strategy and tested for their HIV status accordingly. (data not shown) Similar findings are also reported from Cameroon where 91.3\% of the mothers were tested for HIV during pregnancy and delivery $(17,19)$.

In conclusion, the study demonstrated the major predictors for making safer choice of infant feeding options ranging from maternal attributes such as mode of delivery, positive attitudes towards infant feedings, and disclosure of HIV status to spouse, household income and infant illness. Therefore, to achieve success in exclusivity of feeding options, mothers' decision should be respected, and pressuring the mother by the family/neighbors to introduce other food to the infant should stop. Furthermore, the risks involved in each infant feeding option should be communicated to the mother/father during PMTCT to make informed safer choices. Continuing advocacy work on the options of feeding and involving spouses in every health and nutrition education session to help mothers choose safer infant feeding options is very important.

\section{Acknowledgements}

The authors acknowledge the financial support from the EPHA (Ethiopian Public Health Association) and technical support provided by Addis Ababa University and Addis Ababa Health Bureau. The support obtained by the respective health institutions of Addis Ababa Region as well as all the mothers and health personnel who participated is highly appreciated. This paper is part of a thesis submitted for degree of Master of Public Health.

\section{References}

1. WHO. Breastfeeding and replacement feeding practices in the context of mother to child transmission of HIV: An assessment tool for research WHO/RHR/01.12, WHO/CAH/01.21, Distr: General: 2003;3-20.

2. European Collaboration study. HIV infected pregnant women and vertical transmission in Europe since 1986. AIDS 2001;15:761-770.

3. UNAIDS. AIDS epidemic update: Dec 2007.Geneva, Switzerland; UNAIDS: 2007. Available at www.unaids.org. Accessed on 7/7/2008.

4. Max E. AIDS in Africa, 2nd edition, Kluwer Academic, New York, 2002:251-568.

5. UNAIDS. Linkage project: Breast feeding and HIV/AIDS Frequently Asked Questions (FAQ), 2004, FAQ sheet 1, page 1-5.
6. UNAIDS. Linkages. Infant feeding options in the context of HIV, Academy for Educational Development, Washington, DC 20009. April 2004:317.

7. UNAIDS. HIV and Infant feedings: A guide for health care managers and Supervisor, 1999, Switzerland, Geneva, 24-58.

8. FMOH. AIDS Report $6^{\text {th }}$ Edition, Addis Ababa, Ethiopia, Federal Ministry of Health, 2006; 3-10.

9. FHAPCO and FMoH. Guideline for prevention of mother to child transmission of HIV in Ethiopia: Federal HIV/AIDS Prevention and Control office, Federal Ministry of Health. July 2007, 3-12.

10. Aika A, Omari, C.L. Infant feeding practices of mothers of known HIV status in Lusaka, Zambia. Health Policy and Planning 18(2): 156-162.

11. Senyonga R, Muwonge R, Nankya I. Towards a Better Understanding of Exclusive Breastfeeding in the era of HIV/AIDS: A Study of Prevalence and Factors Associated with Exclusive Breast from Birth, in Rakai, Uganda. Journal of Tropical Pediatrics December 2004; 50(6): 348-353.

12. Addis Ababa Region 14 Health Bureau. Activity report, Addis Ababa; 2006/2007.

13. Kassahun D, Jennifer R, Nadra F, Agnes G. Prevention of mother to child transmission (PMTCT): baseline survey, 2004, Addis Ababa, Ethiopia, page 15-43.

14. Meselech A. Assessment of intention and practice of VCT and infant feeding in the context of HIV/AIDS among lactating mothers in Harar town, March 2006,23-24. Master thesis submitted to Community Health Department.

15. Bland RM, Little $\mathrm{K}$. Intervention to promote exclusive breast-feeding for the first 6 months of life in a high HIV prevalence area, South Africa. AIDS 22 (7):883-891.

16. WHO. Regional Office for Africa, IMCI (Integrated Management of Childhood Illness) Infant and Young Child Feeding: News letter, September 2002;5(3).

17. Njom NA, Penda I, Same E.C, et al. International Conference on AIDS (15th:2004: Bangkok, Thailand). Factors associated with infant feeding choices of HIV positive mothers in urban areas. Cameroon. Int. Conf. AIDS 2004;15:11-16.

18. Nishi S, Sasi J, Ashwini S, et al. Infant Feeding Practices of HIV Positive Mothers in India, Johns Hopkins University, Pune, India. The American Society for Nutritional sciences J. Nutr. May 2003; 133:1326-1331.

19. Leshabari S, Sebalda C. Infant feeding in the context of HIV infection: mothers' experiences and program implications for maternal and child health services in Tanzania. The university of Burgen, 29-Feb-2008; ISBN: 978-82-308-0526-8. 